\title{
Relationships, Human Behaviour and Financial Transactions
}

\author{
Mehdi Chowdhury \\ Business School, Bournemouth University, Bournemouth, UK \\ Email: mchowdhury@bournemouth.ac.uk
}

Received 17 October 2014; revised 26 November 2014; accepted 8 December 2014

Copyright (C) 2014 by author and Scientific Research Publishing Inc.

This work is licensed under the Creative Commons Attribution International License (CC BY). http://creativecommons.org/licenses/by/4.0/

(c) (i) Open Access

\begin{abstract}
It is widely known that relationships and human behaviours such as trust, reciprocity and altruism that are observed in the human societies are capable of facilitating financial transactions. This paper proposes a theoretical model to argue that though these elements can facilitate financial transactions, they may not always ensure efficiency in the sense of creation of additional wealth. As financial resources are scarce, the paper argues that the financial transactions induced by relationships, trust, reciprocity and altruism may lead to inefficient allocations of resources.
\end{abstract}

\section{Keywords}

\section{Efficiency, Human Behaviour, Financial Transactions}

\section{Introduction}

The importance of relationships in financial intermediation is well recognised in the banking and finance literature. Financial intermediaries often confront the problem of information asymmetry and long established relationships between the lenders and borrowers can overcome this (Boot, 2000) [1]. Apart from relationships, recent works by experimental economists have well established that financial transactions can also be facilitated by human behaviours like altruism, trust and reciprocity (Fehr and Schmidt, 2006 [2]). The importance of these behavioural elements has been also recognised by the economists who tried to explain the reasons for intrafamily financial transfers. A survey of literature on intra-family financial transfers is available in Laferrère and Wolff (2006) [3].

This paper asks if the financial transactions induced by relationships, trust, reciprocity and altruism can automatically ensure "Efficiency" in the sense of creation of additional wealth that market is otherwise unable to provide? It can be explained further by referring to an experiment conducted by Berg et al. (1995) [4]. In the experiment a subject " $A$ " transfers a fraction from his initial endowment of $\$ 10$ to an anonymous subject " $B$ ". 
The amount transferred is multiplied by 3. B then transfers a fraction of that amount to A. Rationality or selfishness implies that subject A should not transfer any amount to B and B should not transfer any amount to A. This attitude however is not maximising their joint wealth, as, if A transfers no amount to B, then the total wealth is only $\$ 10$ compared to the possible maximum of \$30. Transactions are Pareto improving when A trusts $\mathrm{B}$ and transfers some money and B reciprocates by returning the money transferred by A.

In the actual economy resources are scarce and financial intermediaries are often credit constrained. Extending credit for one purpose implies a lack credit of for another purpose. Therefore relationships, trust, reciprocity and altruism can crowd-out rule based lendings. The transactions as addressed in Berg et al. (1995) [4] improve the joint welfare. There should be no objection if transactions based on relationships and behavioural elements always create additional wealth. The paper questions if it is the case all the time and argues that it is not. Actually some transactions can be wealth reducing, that is total wealth is higher if relationships or behavioural elements fail to initiate transactions in the first place. This has been illustrated by a theoretical example of a simple principal-agent model, where the principal transfers money to the agent after receiving a guarantee from a third party. The basic message of the paper is very straight forward, that is relationships, trust, altruism and reciprocity based transactions can be inefficient. The paper serves to exemplify this message further.

It is possible to find a connection between this paper and the growing literature on individual and corporate social responsibility (Bénabou and Tirole, 2010 [5]; Kitzmueller and Shimshack, 2012 [6]). However, it is more linked to the growing support for relationship-based banking and networking. Though the paper can be viewed as a criticism of relationship-based banking, we are not undermining the importance of it in the actual economy. Its importance is already well established, such as past relationships reduced collateral requirements and also helped obtaining larger loans (Bharath et al., 2011 [7]) and banking relationships contributed in reducing financial tension and credit rationing after the financial crisis of 2008 (Gobbi and Sette, 2013 [8]; Bartolia et al., 2013 [9]).

The structure of the remaining sections of the paper is as follows. The second section describes the model that forms the basis of argument. The third section analyses the conditions where transactions can be efficient or inefficient. The final section concludes the paper by providing a direction for future research.

\section{The Model}

The purpose of this section is to introduce the model which forms the basis of arguments in the later parts of the paper. We assume that there are three players in the model:

a. The Principal: who gives the loan, denoted as B(anker).

b. The Agent: who receives the loan, $\mathrm{D}$ (ebtor).

c. The Guarantor: who performs the role of a G(uarantor).

B gives loan amount $l$ to $\mathrm{D}$ with an agreement that $r$ will be repaid at the end of a pre-agreed period where $r>$ l. If the amount is not repaid $\mathrm{G}$ is regarded as liable and hence the mechanism solves both adverse selection and moral hazard problems.

The assumptions of the model are,

a. $\mathrm{G}$ is altruistic. Altruism is defined as a mental condition as such $\mathrm{G}$ gets a psychological benefit from doing something good for D.

b. D reciprocates the behaviour of G. D aims to completely repay the loan so that G does not have to bear the burden of repayment of the loan.

c. B gives the loan on the basis of relationship or trust in G. The relationship and trust can be formed by mutual long term business/social interactions or by availability of collateral to support the loan repayment ${ }^{1}$. B is not altruistic to G or D. B only cares about loan repayment and does not attach any value to the sources of repayment.

The timeline of the acts are as follows: B lends $l$ to D with a written or non-written contract which is enforceable under any contingencies. D invests in the project and exerts effort. The outcome is obtained and $r$ amount is repaid to B irrespective of the outcome of the investment. The repayment may come from D or G or a combination of both. There is no uncertainly in repayment.

Relationships allow financial institutions to accumulate information about clients over a longer period of time

${ }^{1}$ Social norms can play an important role in enforcing contracts in the absence of formal enforcing mechanisms. Social norms may require $\mathrm{G}$ under any contingencies, reciprocates the trust of B by ensuring the repayment of the loan. 
and to develop trust and mutual understanding between banks and clients. As Boots (2000) [1] mentioned, relationship-based banking leads to the choice between rules and discretion where discretion allows decision making based on non-contractable information. There is therefore a trade-off in the use of relationships in financial lending from bank's point of view. The paper is not concerned about this trade off as the bank always makes profit from the lending.

The investment $l$ gives return $\theta(l)^{2}$ with probability $p$ and 0 with probability $1-p$. The probability of the return depends on the effort of $\mathrm{D}$. Following the convention of notation, we denote effort level as $e$. The probability is given as $p(e)$ which is concave in effort as such $p^{\prime}>0$ and $p^{\prime \prime}<0$. The effort is defined not in term of personal unobservable endeavour but rather as the personal investment of $\mathrm{D}$ in the project, which is expressible in monetary term. As $p(e)$ is concave, the effort of $\mathrm{D}$ increases the probability of success of the project which implies that the project becomes more capable of attaining the objective. It is possible that $\theta$ goes up as $e$ goes up. We ignore that possibility to keep the exposition simple.

Expected pay off of the project therefore is:

$$
E=p(e) \times \theta+(1-p(e)) \times 0=p(e) \theta
$$

The income of $\mathrm{D}$ from the project minus repayment of loan is:

$$
I=p(e) \theta-e-r
$$

The project is viable if $I>0$. To facilitate loan repayment from only the gross revenue of the project, the project needs to generate sufficient gross revenue so that following inequality is satisfied:

$$
Q=p(e) \theta-r \geq 0
$$

The gross revenue of the project needs to be mentioned specifically as when a project does not perform well, the gross revenue can provide information on repayment possibility. In difficult situations, struggling investors sometimes disregard their own monetary and non-monetary costs and look at gross revenues to repay loans. Equation (3) reflects that situation ${ }^{3}$.

Needless to say that, $p(e) \theta-e$ gives the net revenue of the project.

\section{Economic Efficiency of the Loan}

This section analyses the effort level that D utilises to ensure repayment of the loan. It also analyses if the loan is economically viable, i.e. creates more wealth than what was initially available. It is analysed using following two cases:

Case 1: $p\left(e_{0}\right) \theta-r<0$

Here, with no effort, the expected income from the project is lower than the amount to be repaid. By assumption, the function $p(e) \theta-e$ is concave in effort. Hence it has been drawn in Figure 1 as the concave curve denoted by $p(e) \theta-e$. The project is not economically viable as $p(e) \theta-e$ is never greater than $r$. The optimum loan of the project is therefore $l=0$.

However, given the ex-ante situation that $l>0$ and the investment has been made, the agent uses effort level $e^{*}$ if he wishes to minimise the gap between $r$ and the net revenue of the project. But a reciprocal individual may not stop there. In order to repay the loan the project must generate sufficient funds. D being a reciprocal individual may ignore personal investment costs and choose to use effort up to the level where $p(e) \theta=r$. Such a point is defined by $e_{m}$. Otherwise D may reciprocate by using effort up to $e^{*}$ and then supplement the remaining amount from additional resources.

The meaning of the effort $e$ of the $\mathrm{D}$ (ebtor) here requires further attention. $e$ is defined as D's own investment in the project. If the first derivative is positive when $e=0$, D should use some effort in the project. It is however subject to a limit. If the own investment of $\mathrm{D}$ has an upper bound, it may prohibit generation of sufficient funds. If this is the case then the only way the loan can be repaid is through transfer of the guarantor G's fund to $\mathrm{B}$.

Case 2: If $p\left(e_{0}\right) \theta-r \geq 0$

Here the project is viable, as without any effort, $\mathrm{D}$ gets a non-negative return from the project. The situation is depicted in Figure 2. Given that $p(e) \theta-e$ is concave and first derivative is positive when $e=0$, the value of

${ }^{2}$ We assume $\theta^{\prime}>0$ and $\theta^{\prime \prime}<0$.

${ }^{3}$ This observation comes from the author's personal experience of working in a bank. 


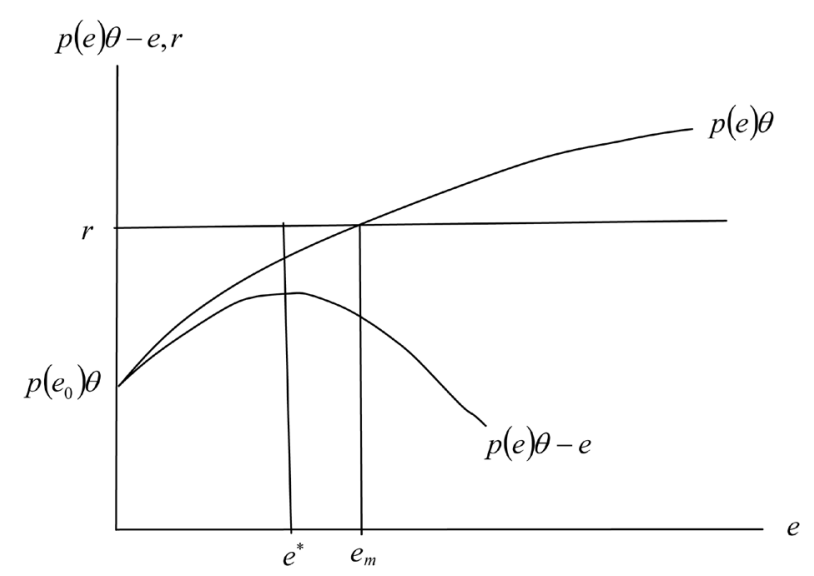

Figure 1. The project is not economically viable.

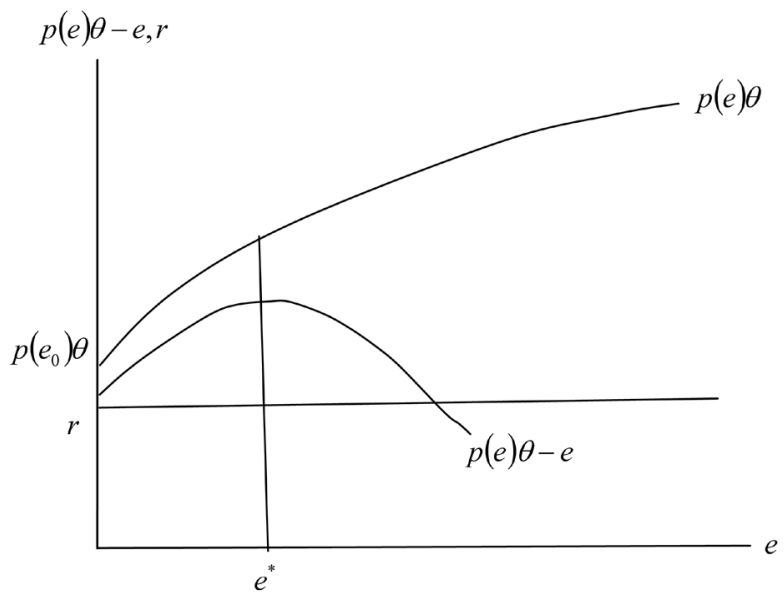

Figure 2. The project is economically viable.

the function $I=p(e) \theta-e-r$ increases initially with the effort level, and then after some level it falls. It gives the optimum effort level of the project $e^{*}$. Hence the agent undertakes the project with ex-ante information of $\theta$. That is, even before the loan is given to him through the guarantee of $\mathrm{G}$.

In case 2, the project is viable even without any effort of D. It is also possible that $p\left(e_{0}\right) \theta-r<0$; however, $p(e) \theta-e-r \geq 0$ for some $e$. In that case the project is also viable and D invests when information on the return of the project is ex-ante available.

We are now ready to analyse the efficiency of the transactions that is if the transactions create more wealth. Our benchmark here is the loan $l$ that has been transferred to D. If total wealth created is more than $l$ then transactions involving B, G and D are wealth improving. G may or may not transfer some money from his own fund to B, which gets cancelled in calculation. Therefore, we only calculate efficiency by taking the monetary benefit of the principal and the agent into consideration which are:

The Principal (B): $r-l$

The Agent (D): $p(e) \theta-e-r$

The motive of the guarantor $\mathrm{G}$ is altruistic. We assume that it is non-expressible in monetary terms ${ }^{4}$. Therefore, in total, the monetary benefit of society from the transactions is $r-l+p(e) \theta-e-r=p(e) \theta-e-l$. As $r>l$ by assumption (assured through the guarantee of G), B is always willing to extend loan to D irrespective of the outcome of the project and the transactions improve his wealth. The benefit of $\mathrm{D}$ can be negative or positive as observed in case 1 and case 2. However, even if the benefit of the D is negative there is a possibility at margin that $p(e) \theta-e-l \geq 0$ as $r>l$ i.e. if the loss of $\mathrm{D}$ is compensated by the benefit of $\mathrm{B}$. The wealth of

\footnotetext{
${ }^{4}$ Note that the emphasis of the paper is to evaluate the monetary benefit of transactions, not the social welfare. This is applicable where any mechanism of transforming the intrinsic satisfaction of $\mathrm{G}$ to monetary values is absent.
} 
society increases when $p(e) \theta-e-l>0$. This is not ensured with certainty as it is also possible to have $p(e) \theta-e-l<0$. Therefore the transactions do not necessarily improve the wealth of society. As we discussed earlier, the basis of these transactions is formed by relationships, trust, reciprocity and altruism. In case 2, it actually leads to efficiency as the transactions create more wealth than the initial amount. However, in case 1 the same transactions take place on the basis of relationships, trust, reciprocity and altruism but create less wealth.

The findings of the case 1 crucially depends on the assumption that $\theta$ and $p(e)$ are unknown ex-ante, otherwise a rational agent would not take the loan. A scenario like case 1 is unlikely to be observed in formal bank lendings. Formal banking applications for loan often require formal project proposals that provide a prior understanding of a project's expected return. The process makes it is possible for a financial institution (and also the borrowers) to, with some error, correctly predict the possibility of repayment from a project's income. The informal lending institutions however, may not ask for any formal project proposal. The approval of loans in informal settings depends on the willingness and repayment capability of the borrowers. An existence of business or social relationships may convey that assurance to the lender. On the other hand, when made available, borrowers sometimes take loan without paying enough attention to the repayment possibility. The lenders' willingness to lend and the borrowers' willingness to take loan in an informal setting can hence result in a situation like case 1 . We however suggest for conducting empirical analysis to further testing the validly and applicability of the analysis in the real world.

\section{Lessons and Conclusions}

This paper provides a simple model to show that relationships, trust, reciprocity and altruism may provide solutions where regular market mechanisms fail but they do not automatically guarantee additional wealth. In the example of Figure 2, the project is capable of generating sufficient funds, but the example in Figure 1 shows the incapability of a project in generating sufficient funds for repayment of the loan.

We therefore can conclude that as resources are scarce, relationship, trust, reciprocity and altruism based financial intermediation may result in a suboptimal use of financial resources. The growing support for relationships, networking and emphasis of human behavioural elements are overlooking this possibility. The paper used a theoretical example, validity of which needs to be evaluated through empirical investigations. We therefore suggest for conducting empirical investigations on the subject matter, especially on financial intermediations in less developed countries where regulations and governance of financial institutions are known to be less transparent.

\section{Acknowledgements}

The author would like to express gratitude to Davide Secchi, Jens Hölscher, Sue Barnes and the seminar participants at Bournemouth University, UK. All the remaining errors are the author's.

\section{References}

[1] Boot, A. (2000) Relationship Banking: What Do We Know? Journal of Financial Intermediation, 9, 7-25. http://dx.doi.org/10.1006/jfin.2000.0282

[2] Fehr, E. and Schmidt, K. (2006) The Economics of Fairness, Reciprocity and Altruism: Experimental Evidence and New Theories. In: Kolm, S.C. and Ythier, J.M., Eds., Handbook of Economics of Giving, Altruism and Reciprocity, 615-691.

[3] Laferrère, A. and Wolff, F.C. (2006) Microeconomic Models of Family Transfers. In: Kolm, S.C. and Ythier, J.M., Eds., Handbook of Economics of Giving, Altruism and Reciprocity, 889-969.

[4] Berg, J., Dickhaut, J. and McCabe, K. (1995) Trust, Reciprocity and Social History. Games and Economic Behavior, 10, 122-142. http://dx.doi.org/10.1006/game.1995.1027

[5] Bénabou, R. and Tirole, J. (2010) Individual and Corporate Social Responsibility. Economica, 77, 1-19. http://dx.doi.org/10.1111/j.1468-0335.2009.00843.x

[6] Kitzmueller, M. and Shimshack, J. (2012) Economic Perspectives on Corporate Social Responsibility. Journal of Economic Literature, 50, 51-84. http://dx.doi.org/10.1257/jel.50.1.51

[7] Bharath, S., Dahiya, S., Saunders, A. and Srinivasan, A. (2011) Lending Relationships and Loan Contract Terms. Review of Financial Studies, 24, 1141-1203. http://dx.doi.org/10.1093/rfs/hhp064 
[8] Gobbi, G. and Sette, E. (2013) Do Firms Benefit from Concentrating Their Borrowing? Evidence from the Great Recession. Review of Finance, 18, 527-560. http://dx.doi.org/10.1093/rof/rft017

[9] Bartolia, F., Ferrib, G., Murroc, P. and Rotondia, S. (2013) Bank-Firm Relations and the Role of Mutual Guarantee Institutions at the Peak of the Crisis. Journal of Financial Stability, 9, 90-104. http://dx.doi.org/10.1016/j.jfs.2012.03.003 
Scientific Research Publishing (SCIRP) is one of the largest Open Access journal publishers. It is currently publishing more than 200 open access, online, peer-reviewed journals covering a wide range of academic disciplines. SCIRP serves the worldwide academic communities and contributes to the progress and application of science with its publication.

Other selected journals from SCIRP are listed as below. Submit your manuscript to us via either submit@scirp.org or Online Submission Portal.
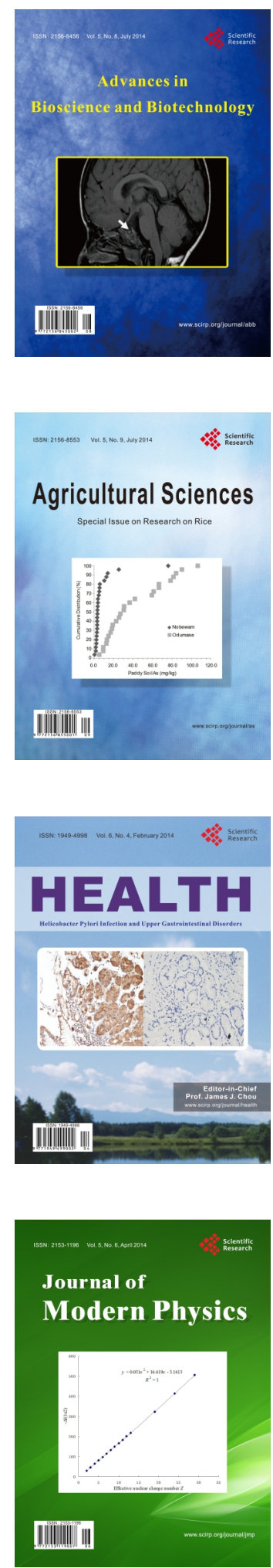
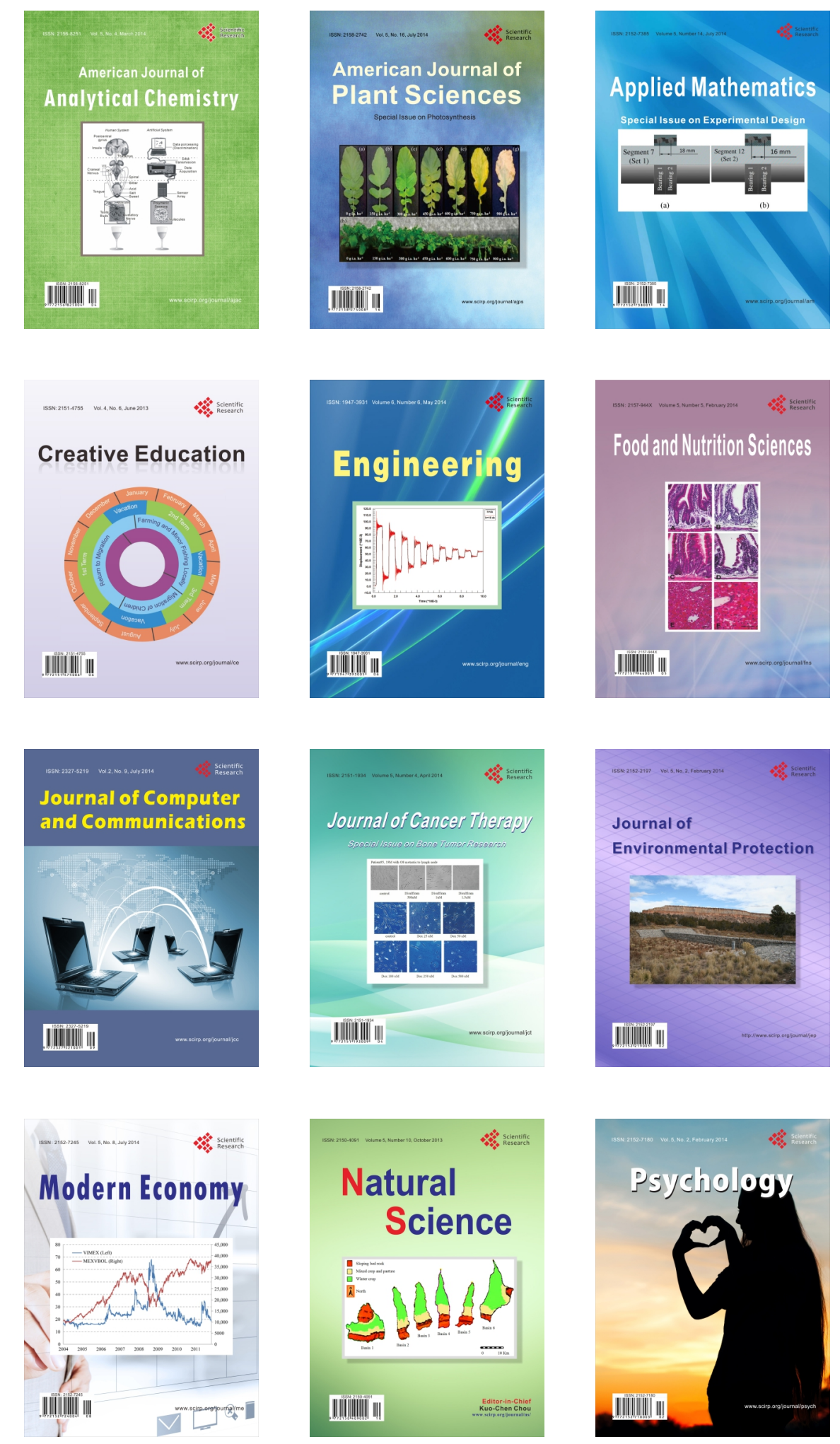